\title{
A DIFFERENT APPROACH IN OPTIMUM DESIGN PROCESS USING ACO ALGORITHM AND FEA VALIDATION OF LOW-SPEED MULTI-PHASE IPMSMS
}

\author{
HAMid REZa GHOLineJAd OMran AND SAYYed ASGHAR GHOLAMiaN* \\ Department of Electrical and Computer Engineering, \\ BABOL Noshirvani University of Technology, Babol, Iran. \\ *Corresponding author: gholamian@nit.ac.ir

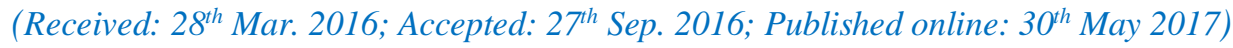

\begin{abstract}
Magnet placement affects the performance of permanent magnet motors through changes to the magnetic flux density distribution. Therefore, different magnet placements should be examined experimentally or by valid simulations. In this paper, an interior permanent magnet synchronous motor (IPMSM), called a spoke type, with specifications related to the propulsion of ships is designed and then optimized by ant colony optimization (ACO) algorithm to increase the torque-to-volume ratio. The design procedure and its formulas are presented as simply as possible. Based on these formulas, motor torque of about $16 \mathrm{kNm}$ in a volume of $0.87 \mathrm{~m}^{3}$ was obtained. Then, to verify the optimization results of the optimized motor, a two-dimensional finite element analysis (FEA) is done. The error rate of the results was below 5\%. Also in this analysis, the core and the slot saturation were studied.
\end{abstract}

ABSTRAK: Penempatan magnet memberi kesan kepada prestasi magnet motor kekal melalui perubahan kepada pengedaran ketumpatan fluks magnet. Oleh itu, penempatan magnet yang berbeza perlu diperiksa secara eksperimen atau dengan simulasi sah. Dalam kertas ini, motor segerak magnet kekal dalaman (IPMSM), yang dipanggil jenis spoke, dengan spesifikasi yang berkaitan dengan pendorongan kapal direka dan kemudian dioptimumkan oleh algoritma ant colony pengoptimuman (ACO) untuk meningkatkan nisbah tork-kepada-isipadu. Prosedur reka bentuk dan formula dikemukakan secara mudah. Berdasarkan formula ini, tork motor kira-kira $16 \mathrm{kNm}$ dalam isipadu $0.87 \mathrm{~m} 3$ telah diperolehi. Kemudian, untuk mengesahkan keputusan pengoptimuman motor yang optimum, satu analisis kaedah unsur finite dua dimensi (FEA) telah dilakukan. Keputusan menunjukkan kadar ralat adalah di bawah 5\%. Analisis ini juga membuat kajian mengenai teras dan tepu slot.

KEYWORDS: interior permanent magnet synchronous motor; ant colony optimization; finite element analysis

\section{INTRODUCTION}

Electric motors are one type of ship propulsion. Their power depends on the ship weight and the number of ship propulsion sources. Most of these motors work at low speeds and their operational voltage is between 400 volts and several kilovolts [1]. Permanent magnet (PM) motors can be a choice for this application. PM motors present multiple benefits that have led to their use in many applications. Increasing the phase number of these motors increases the fault tolerance and reliability but reduces the stator current (per phase) and harmonics in DC links compared to the conventional three-phase motors $[2,3,4]$. Nowadays, advances that are obtained in the power electronics field have made it possible to implement more phases properly. Therefore, in this paper, a multi- 
phase PM motor will be investigated according to ship propulsion characteristics. A summary review of several related researches is given here.

The advantages of a Five-Phase permanent-magnet motor are presented in [2]. The results show better performance of this motor than the three-phase PMSM and BLDC counterparts. In [3], a Five-Phase Halbach array permanent-magnet machine is optimized by genetic algorithm method to increase efficiency, acceleration, and output power. To achieve this goal, the analytical model of this motor based on motor geometrical and materials data is presented. In [5], using a new algorithm belonging to the class of controlled random search algorithms, a multi-objective optimization is done to decrease the weight and increase the efficiency of an interior permanent magnet synchronous motor. Therefore, two motors with different speed and different output power have been optimized. One of them was single-layer buried magnet and the other one was doublelayer. In [6], Ant Colony Optimization (ACO) is used to optimize a magnet synchronous motor with surface permanent magnet topology. This algorithm has been applied to search for the optimum motor geometry. In this paper, error rate of 5\% is considered to stop the algorithm. In [7], a systematic comparison of flat type, V-type, and spoke-type IPM machines is provided. To optimize the material cost, power losses, and the torque ripple of these motors, a combined multi-objective design optimization method employing design of experiments and differential evolution algorithms has been developed which is the most popular optimization method for electric machine design. In [8], after the initial design of a spoke type IPM for low voltage, the main purpose is using finite element analysis to improve its torque quality. So, in [8], a different number of segmented rotors and a changing mechanical air gap are used.

According to these researches, this paper intends to provide a design procedure of a five-phase interior synchronous motor to be used as ship propulsion. The magnet placement in the rotor is at the wheel spokes and the optimal performance of this type compared to others is shown in a variety of researches [7-11]. In continuous operation, this motor will be optimized by an ACO algorithm to reduce the size and increase the efficiency and torque. Also, with the aim of achieving ship propulsion specifications, the optimization inputs will be considered in their acceptable ranges. Then, based on optimal results, the motor will simulated based on FEA and some cases such as copper losses, motor torque, air gap flux density, teeth and stator yoke saturation will studied to validate.

\section{DESIGN PROCEDURE}

In motor design, determination of two types of initial parameters is essential. In fact, with the determination of these parameters, the design procedure will begin. The first types are determined by the motor application (according to customer requirements) such as the output power, the voltage, the applied frequency, and the rated speed, which are constant during the design procedure, whereas the second types are determined by the assumptions and experience of the designer and data sheets. The specific electrical loading, specific magnetic loading, excitation electromotive force (EMF)-to-input voltage ratio, rotor length-to-diameter ratio, and in some cases the efficiency and the power factor are some of these parameters. First, the second types are assumed according to experience or data sheets and then, calculated at the end of each design cycle. The values will be compared and replaced with their previous values. If the percentage of the difference between the calculated values and the assumed values was acceptable, the design procedure will end and the results can be obtained. In the remainder of this section, and in the optimization section, the values of these parameters are given. 


\subsection{Dimensions of the Motor}

Motor dimensions contain rotor and stator dimensions. In this section, these dimensions are calculated by mathematical models of the motor. The dimensions of the magnets are discussed in the rotor section, because in the interior type, the size of magnet needed to provide output power, effects on the rotor yoke dimensions. The calculated dimensions are shown in Fig. 1.

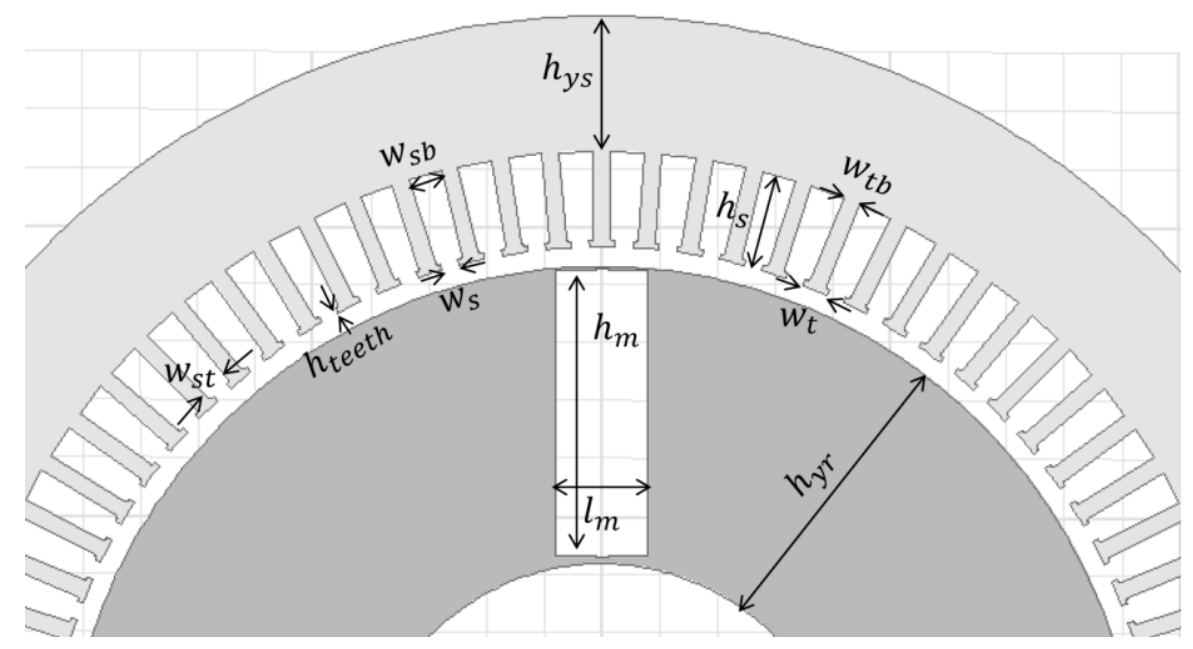

Fig. 1: Dimensions of the motor.

\subsubsection{Rotor Dimensions Calculation}

In Eqn. (1), diameter of the rotor is given by some of the initial parameters [1].

$$
D=\sqrt[3]{\frac{4 m P E_{f} I_{s}}{\sqrt{2} \pi^{4} B_{a v} A_{m} k_{w} k_{s t} \alpha_{\tau} n_{s}}}
$$

where $n_{s}$ is the motor speed in turns on second, $I_{s}$ is the current per stator phase, $m$ is the number of phases, $P$ is the motor poles, and $E_{\mathrm{f}}$ is the excitation EMF. The value and the ranges of other parameters in this equation are listed in Table 1.

Table 1: The value and the ranges of the initial parameters [1]

\begin{tabular}{cc}
\hline Parameters & value and ranges \\
\hline Specific magnetic loading & $0.3 \leq B a v \leq 0.8$ \\
Specific electrical loading & $10000 \leq A_{m} \leq 55000$ \\
Rotor length-to-diameter ratio & $\pi / P \leq \alpha_{\tau} \leq 3 \pi / P$ \\
EMF-to-input & $0.6 \leq E_{f} / V_{i n} \leq 0.95$ \\
Winding step coefficient $\left(\boldsymbol{k}_{\boldsymbol{w}}\right)$ & 1 \\
Core lamination coefficient $\left(\boldsymbol{k}_{\boldsymbol{s}}\right)$ & 0.95 \\
\hline
\end{tabular}

The minimum value of the rotor yoke is calculated by the following equation, where in this equation $[12,13], B_{\mathrm{yr}}$ is the maximum saturated flux density in the rotor core. In this paper, it is considered to be 1.5 Tesla. 


$$
h_{y r}=\frac{\pi B_{a v} D}{2 B_{y r} k_{s t}}
$$

The length of the magnet is equal to the length of the rotor $\left(L=\alpha_{\tau} \mathrm{D}\right)$, but its height $\left(h_{\mathrm{m}}\right)$ and its thickness $\left(l_{\mathrm{m}}\right)$ must be calculated by analysing the specified magnetic equivalent circuit of this type, since they are long and complicated calculations, only the final equation is presented here [14]. Equation (3) is obtained for the magnet height that has an acceptable answer for it (the positive one) [14],

$$
h_{m}=\frac{C_{V} P_{\text {out }}\left(\pi D-\frac{S w_{s}{ }^{2}}{5 g+w_{s}}\right)}{4 \pi \mu_{r} L P B_{a v} f H_{c} D g} \pm \sqrt{\left(\frac{C_{V} P_{\text {out }}\left(\pi D-\frac{S w_{s}{ }^{2}}{5 g+w_{s}}\right)}{4 \pi \mu_{r} L P B_{a v} f H_{c} D g}\right)^{2}-\frac{C_{V} P_{\text {out }}\left(\pi D-\frac{S w_{s}{ }^{2}}{5 g+w_{s}}\right)}{4 \mu_{r} L P^{2} B_{r} f H_{c} L P^{2} g}}
$$

And thus the magnet thickness is obtained by Eqn. (4) [14].

$$
l_{m}=\frac{2 \mu_{r} \tau_{s} g}{\left(B_{r}-\frac{B_{a v} \pi D}{2 P h_{m}}\right)\left(\tau_{s}-\frac{w_{s}^{2}}{5 g+w_{s}}\right)}
$$

In the above equations, $P_{\text {out }}$ is the motor output power that will be determined according to application. $C_{\mathrm{v}}$ is a constant between 0.54 to 3.1 [1]. $\tau_{\mathrm{s}}$ is the slot step and $\mathrm{S}$ is the slot number. $w_{\mathrm{s}}$ is the width of the slot calculates from Eqn. (6) [15]. $\mu_{\mathrm{r}}$ is the relative magnetic permeability. $f$ is applied frequency and $H_{\mathrm{c}}$ is the magnet coercive force. The slot width is considered between two or three folds of the diameter of a conductor, experimentally.

$$
\begin{aligned}
& w_{s}=2 \sim 3 \times \sqrt{4 I_{s} / \pi J_{a}} \\
& g=\left(4 \times 10^{-7} A_{m} \pi D\right) /\left(0.6 \sim 0.8 B_{r} P\right)
\end{aligned}
$$

Where $J_{a}$ is the current density in ampere per square meter with a range related to the cooling procedure of the motor and the type of insulation [1]. Now, according to the height of the magnet and its top and bottom bridge thickness, the rotor yoke can be reformed.

\subsubsection{Stator Dimensions Calculation}

In this section, the slot and stator yoke dimensions are calculated under critical conditions. The critical conditions here mean the slot saturation threshold. Under this condition, the stator dimensions are calculated slightly larger. Similar to the Eqn. (2), the minimum value of the stator yoke is calculated by Eqn. (7), where in this equation, $B_{\mathrm{ys}}$ is the maximum saturated flux density in the stator core, which is considered to be 1.5 Tesla in this paper $[12,13]$.

$$
h_{y s}=\frac{\pi B_{a v} D}{2 B_{y s} k_{s t}}
$$


The minimum tooth width is calculated according to maximum flux that can pass through one tooth as follows [12],

$$
w_{t b}=\frac{\pi B_{a v} D}{S B_{t}}
$$

$B_{\mathrm{t}}$ is the maximum saturated flux density in the teeth, which is also 1.5 Tesla. The slot depth can be obtained by calculating the slot area in two ways (according to the crosssection of conductors placed in one slot and according to motor core geometry). By equalizing these two equations, a quadratic equation is obtained. Then, slot depth can be calculated according to Eqn. (9). This equation has an acceptable answer for the slot depth (the positive one).

$$
h_{s}=\left(\frac{B_{a v} D}{2 B_{t}}-\frac{\left(D+2 g+2 h_{\text {teeth }}\right)}{2}\right) \pm \sqrt{\left(\frac{\left(D+2 g+2 h_{\text {teeth }}\right)}{2}-\frac{B_{a v} D}{2 B_{t}}\right)^{2}+\frac{S I_{s}}{\pi J_{a}}}
$$

$h_{\text {teeth }}$ has been shown in Fig. 1 and its value is about 1 to $2 \mathrm{~mm}$. After determining the slot depth, $w_{\mathrm{sb}}$ and $w_{\mathrm{st}}$, can be obtained by calculating the slot pitch in bottom and top of the slot and subtracting width of a tooth from them. These parameters are given in the following equations;

$$
\begin{aligned}
& w_{s b}=\frac{\pi}{s}\left(D+2 g+2 h_{s}\right)-w_{t b} \\
& w_{s t}=\frac{\pi}{s}(D+2 g)-w_{t b}
\end{aligned}
$$

Since the slot pitch is obtained by summing the width of top of the tooth and slot width, so it can be concluded that:

$$
w_{t}=\tau_{s}-w_{s}
$$

\subsection{Motor Torque Calculation}

This parameter is very important in propulsion applications where high torque at low speed is needed to move a very heavy vehicle. The interior permanent magnet motors are known as salient-pole motors. Because of the changes in the effective air gap length and as a result, changes in the inductances. Therefore, in addition to synchronous torque, these motors have reluctance torque, too. Thus, interior permanent magnet motors can achieve higher torque than the surface mounted type $[1,14,15]$. The electromagnetic torque in electrical motors is $[1,14]$;

$$
T=\frac{m P}{2 \pi f}\left[I_{q} E_{f}+I_{d} I_{q}\left(X_{d}-X_{q}\right)\right]
$$

In this equation, $I_{\mathrm{q}}$ and $I_{\mathrm{d}}$ are the $\mathrm{d}$-q-axis of the stator current and $X_{\mathrm{q}}$ and $X_{\mathrm{d}}$ are the d-q axis of synchronous reactances. Achieving a torque value based on Eqn. (13) seems too hard, because of difficulties in calculating its parameters. This paper proposes a simpler method to achieve the motor torque. The method is using the following equation [1]. 


$$
T=\frac{P\left(P_{i n}-P_{c u}\right)}{4 \pi f}
$$

Where, $P_{\text {in }}$ is the input power and $P_{\text {cu }}$ is the copper losses. Torque value calculated by Eqn. (13) and Eqn. (14) are equal to each other, but Eqn. (14) is simpler. The copper losses are given in Eqn. (15). This equation is reformed according to motor dimensions and considering the end-winding effect [16],

$$
P_{c u}=2 m \rho N_{p h} J_{a}\left(L+\frac{\pi}{4}\left(w_{t}+\left(\frac{\pi\left(D+2 h_{s}\right)}{s}\right)\right)+k_{o v}\left(y_{q}-1\right)\left(\frac{\pi\left(D+2 h_{s}\right)}{s}\right)\right) I_{s}
$$

$\rho$ is the conductors' resistivity and is equal to $1.68 \times 10^{-8}$ for copper. The value and definition of some other parameters in the Eqn. (15) are brought in Table 2.

Table 2: The value and the ranges of Eqn. (11) parameters [12]

\begin{tabular}{cc}
\hline Parameters & value and ranges \\
\hline Copper resistivity & $\rho=1.68 \times 10^{-8}$ \\
Current density & $3 \leq J_{a} \leq 25$ \\
A practical value & $1.6 \leq k_{o v} \leq 2$ \\
Coil pitch & $y_{q}=\operatorname{Int}(S / P)$ \\
\hline
\end{tabular}

\section{OPTIMIZATION METHOD}

In this section, to achieve the main purpose of this article, an effective cost function is defined and optimization will be done based on an ACO algorithm. The main purpose of this article is the torque-to-volume ratio increasing in the permanent magnet motors based on the equations that are provided in the previous section. The considered cost function in this paper is as follows;

$$
F_{c}=\frac{1}{\frac{V_{\min }}{V}+\frac{T}{T_{\max }}}
$$

Where, $V$ is the motor volume (during optimization) and $V_{\min }$ is the least possible volume in the solution space. Similarly, $T_{\max }$ is the maximum value of the motor torque. In the above equation, the influence of the specific magnetic loading, specific electrical loading, rotor length-to-diameter ratio and motor speed to increase the torque-to-volume ratio of the motor are considered.

\subsection{ACO Algorithm}

This algorithm is based on aspects of the behavior of ants. As mentioned in introduction section, this algorithm has repeatedly been used in previous research, and all of these showed good performance. The pseudo-code of this algorithm is shown in Table 3 and its flowchart is shown in Fig. 2 [17]. 
Table 3: Pseudo-code for Ant Colony [17]

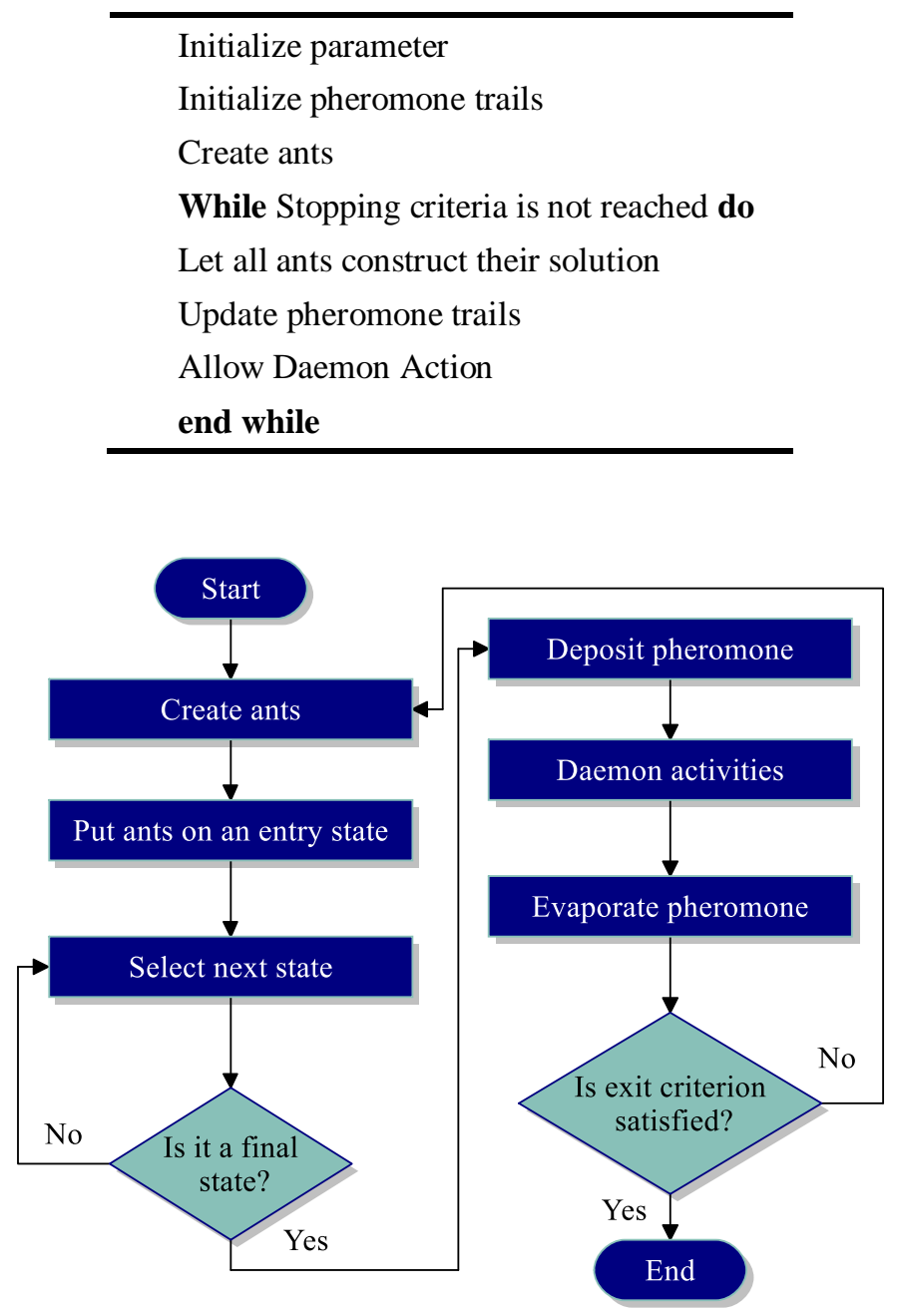

Fig. 2: Flowchart of the ACO algorithm.

Based on $\mathrm{ACO}$, the transition rule quantifies the probability of an ant $k$, positioned at city $i$, traveling to city $j$, and given by:

$$
P_{i j}^{k}(t)=\frac{\left[\tau_{i j}(t)\right]^{\alpha} \cdot\left[1 / \sqrt{\left(x_{i}-x_{j}\right)^{2}+\left(y_{i}-y_{j}\right)^{2}}\right]^{\beta}}{\sum_{l \grave{a} J_{i}^{k}}\left[\tau_{i l}(t)\right]^{\alpha} \cdot\left[1 / \sqrt{\left(x_{i}-x_{j}\right)^{2}+\left(y_{i}-y_{j}\right)^{2}}\right]^{\beta}}
$$

Where, $\left(\mathrm{x}_{\mathrm{i}}, \mathrm{y}_{\mathrm{i}}\right)$ and $\left(\mathrm{x}_{\mathrm{j}}, \mathrm{y}_{\mathrm{j}}\right)$ are coordinates of the cities $\mathrm{i}$ and $\mathrm{j}$ respectively. $\alpha$ and $\beta$ are weighting parameters for the pheromone and the distance between cities $i$ and $j . \tau_{\mathrm{ij}}(t)$ is the pheromone in each arc. The evaporation process simulated by Eqn. (18) applies an evaporation rate $\gamma$ between 0 and 1 [17].

$$
\tau_{i j}(t+1)=(1-\gamma) \cdot \tau_{i j}(t)
$$

As $\gamma$ value gets closer to 0 , the pheromone importance increases. The pheromone quantity deposited in each arc can be expressed by the Eqn. (19) [17], 


$$
\Delta \tau_{i j}(t)=\sum_{k=1}^{m} \frac{Q}{S^{k}(t)}
$$

where, $Q$ is a positive parameter and $S^{\mathrm{k}}(t)$ is the length of the tour constructed by ant $k$ at interaction $t$. The value of algorithm parameters are: $\alpha=1, \beta=3, Q=100, \rho=0.4$ and $\tau_{0}=0.000001$.

The optimization inputs such as specific magnetic loading, specific electrical loading, separation factor (rotor length-to-diameter ratio), and EMF-to-input ratio are shown in Table 1 . These parameters vary in their ranges to achieve the optimum input.

\subsection{Optimum Design of an IPMSM}

In this section, a five phase spoke type permanent magnet synchronous motor will be optimized to achieve the highest torque-to-volume ratio, based on equations and information that were given in the previous sections. Initial parameters are: power; 160 $\mathrm{KW}$, voltage; $1000 \mathrm{~V}$, and frequency; $25 \mathrm{~Hz}$. Also, motor speed has been considered as one of the optimization variables to find its optimum value between 200 to 800 RPM.

At the first step of this section, two optimizations with a single objective function are done. These functions are the motor torque and the whole motor volume, which result in the maximum torque and the minimum volume. Then, based on Eqn. (16), the optimization with a multi-objective function is done. Based on these optimizations, the maximum torque and the minimum volume value are achieved at $24044 \mathrm{Nm}$ and 0.4584 cubic meters respectively. Optimum input and the results of the multi-objective function are shown in Table 4.

Table 4: The optimization results

\begin{tabular}{ccccccc}
\hline Parameters & values & Unit & & Parameters & values & Unit \\
\hline Volume & 0.8605 & $\mathrm{~m}^{3}$ & & $\boldsymbol{\alpha}_{\boldsymbol{\tau}}$ & 0.8702 & - \\
Torque & 16200 & $\mathrm{Nm}$ & & $\boldsymbol{E}_{\boldsymbol{f}} / \boldsymbol{V}_{\boldsymbol{i n}}$ & 0.81 & - \\
$\boldsymbol{P}_{\boldsymbol{c u} \_\boldsymbol{e} w}$ & 6954 & $\mathrm{~W}$ & & $\boldsymbol{D}$ & 0.9444 & $\mathrm{~m}$ \\
$\boldsymbol{P}_{\boldsymbol{c u} \boldsymbol{u}}$ & 4123.3 & $\mathrm{~W}$ & & $\boldsymbol{L}$ & 0.822 & $\mathrm{~m}$ \\
$\boldsymbol{B}_{\boldsymbol{a} \boldsymbol{v}}$ & 0.5851 & $\mathrm{Tesla}$ & & $\boldsymbol{h}_{\boldsymbol{y} \boldsymbol{r}}$ & 0.119 & $\mathrm{~m}$ \\
$\boldsymbol{A}_{\boldsymbol{m}}$ & 29456 & $\mathrm{~A} / \mathrm{m}$ & & $\boldsymbol{h}_{\boldsymbol{y}}$ & 0.061 & $\mathrm{~m}$ \\
\hline
\end{tabular}

The convergence curve of the ACO algorithm is shown in Fig. 3. In this figure, the curve tends to 0.5 , because each of the parameters (torque and volume) in Eqn. (16) are per-unit. The closer the curve to 0.5 , the better the convergence.

\section{SIMULATION OF AN OPTIMIZED MOTOR}

Before construction, FEA is one of the ways of evaluating the proposed procedure, as its results are very close to experimental results. For this reason, the optimized motor will be simulated by Ansys-Maxwell@ software which is based on FEA. So far, this software 


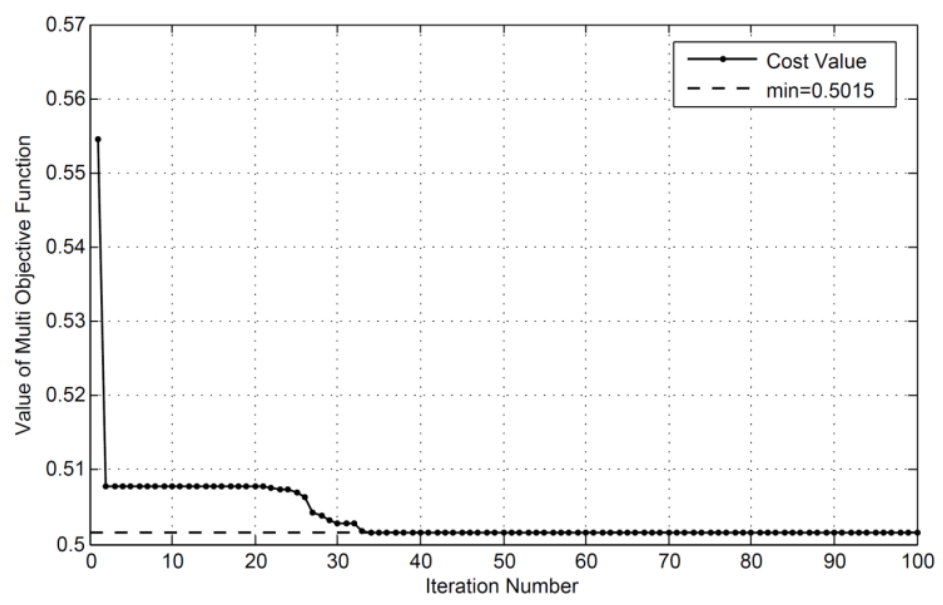

Fig. 3: Convergence curve of the ACO.

has been successfully used in previous research. Some parameters derived from simulation, such as the motor torque, the copper losses and the air gap flux density will be compared with the optimization results to investigate the accuracy of the design procedure. Also, the saturation in the teeth and stator yoke has been explained.

This simulation is done on a 64-bit system that has 3 gigabytes of RAM, and 2.53 $\mathrm{GHz}$ of CPU. The total number of mesh elements is 428588 , the stop time is considered to be 80 milliseconds with $0.1 \mathrm{~ms}$ of step time. A view of the simulated motor is shown in Fig. 4. Also, Table 5 represents the core type and the magnet characteristics used in simulation.

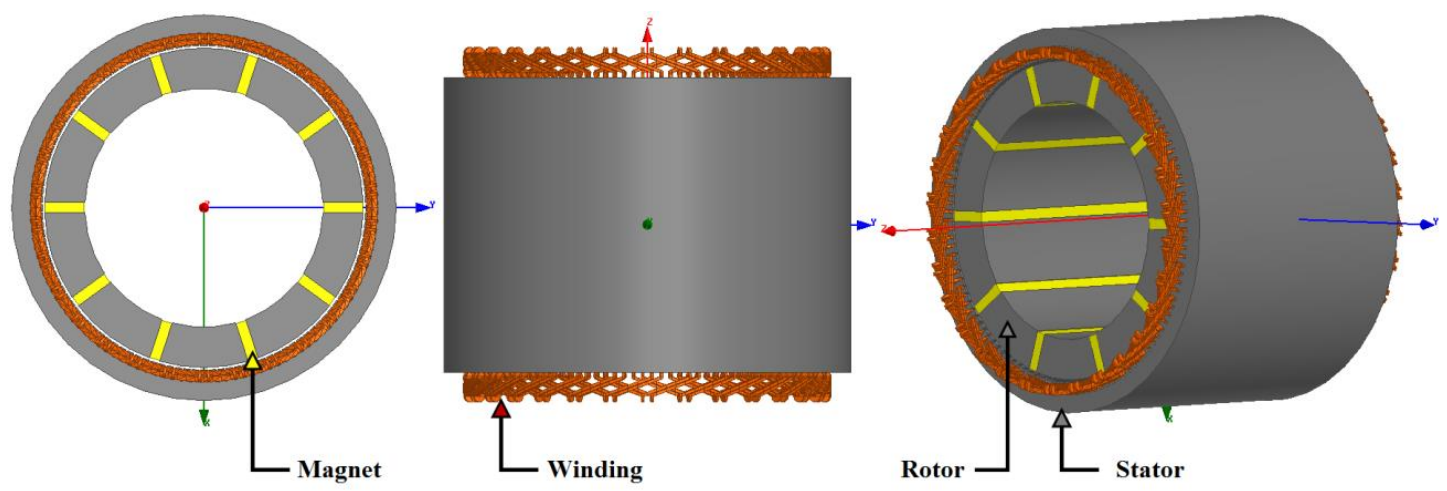

Fig. 4: 2-D and 3-D view of simulated motor.

Table 5: Details of core and permanent magnet characteristics

\begin{tabular}{ccc}
\hline Parameters & Details & Unit \\
\hline Kind of core & M19-24G & - \\
Mass density & 7650 & $\mathrm{~kg} / \mathrm{m}^{3}$ \\
Kc & 0.0154809 & $\mathrm{w} / \mathrm{m}^{3}$ \\
Kh & $6.92096 \mathrm{e}-005$ & $\mathrm{w} / \mathrm{m}^{3}$ \\
Ke & 0.000345255 & $\mathrm{w} / \mathrm{m}^{3}$ \\
Br & 1.2 & $\mathrm{~T}$ \\
Hc & -920000 & $\mathrm{~A} / \mathrm{m}$ \\
\hline
\end{tabular}




\subsection{Results of Simulation}

As shown in Fig. 5, the motor torque average value calculated by simulation is $15.5912 \mathrm{kNm}$ with $3.82 \%$ ripple. This value for torque ripple is acceptable and common in this type of motor, because of their particular structure $[1,4,7,8,15]$. The motor torque value calculated in optimization has less than $4 \%$ difference with the simulation result. Compared to the error in the references $[2,3]$, this error is acceptable and represents the accuracy of the applied equations. There is $0.2 \%$ difference between the average value of flux density calculated by FEA ( 0.58 Tesla) and the optimization result.

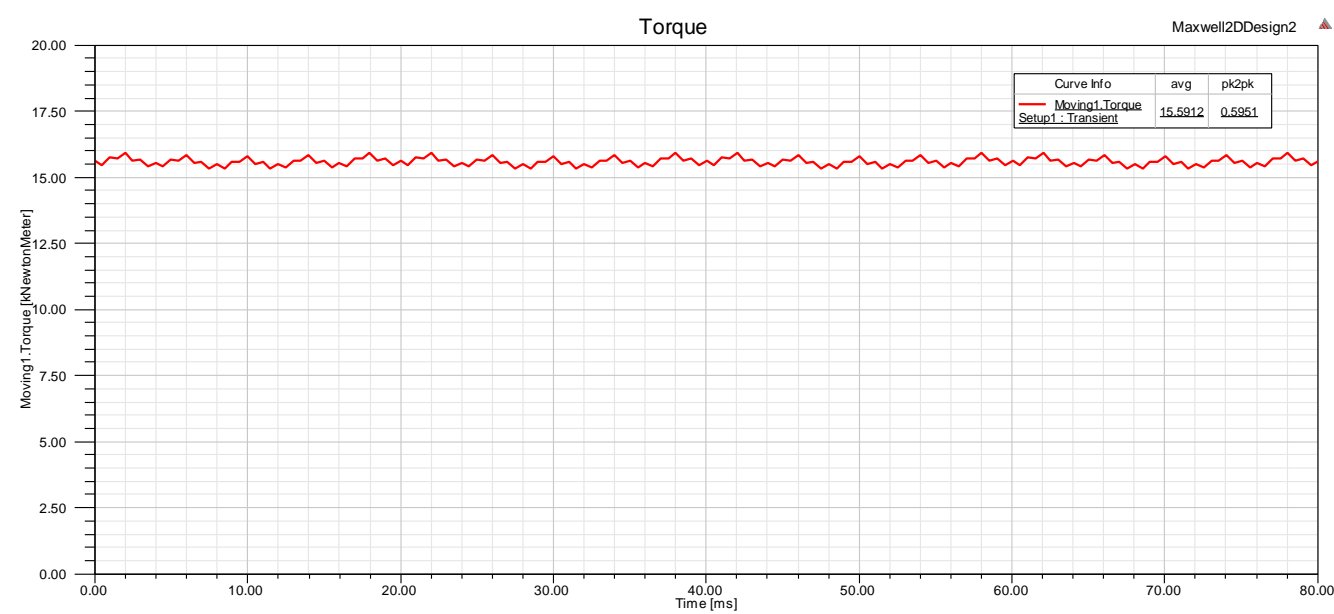

Fig. 5: The curve of the motor torque.

The motor performance, especially motor torque, will be improved as long as the air gap flux density distribution becomes better, because of its effects on whole design process. Figure 6 shows the distribution of the air gap flux density in one pole pitch. Ripple existence in this curve is due to stator slots.

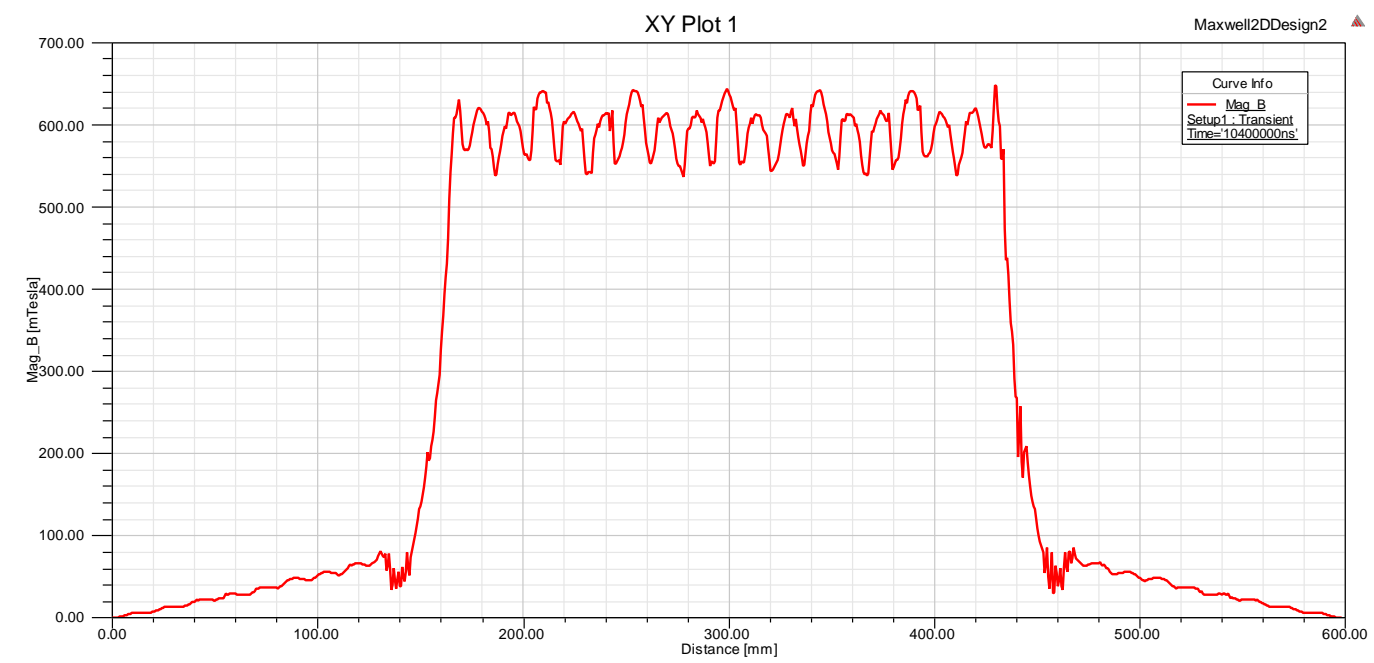

Fig. 6: Air gap flux density changes in one pole.

As mentioned in section 2.2, motor torque can be achieved by calculating copper losses. Since the effect of the end-winding is not taken into account in the twodimensional analysis, Fig. 7 represents the copper losses without considering the effect of end-winding while in the Eqn. (15) it is considered. But, it is possible to calculate copper losses without considering the end-winding effect to compare them more appropriately. 
The copper losses calculated by ACO is $4123.3 \mathrm{~W}$ which has a difference less than $4 \%$ with the FEA result.

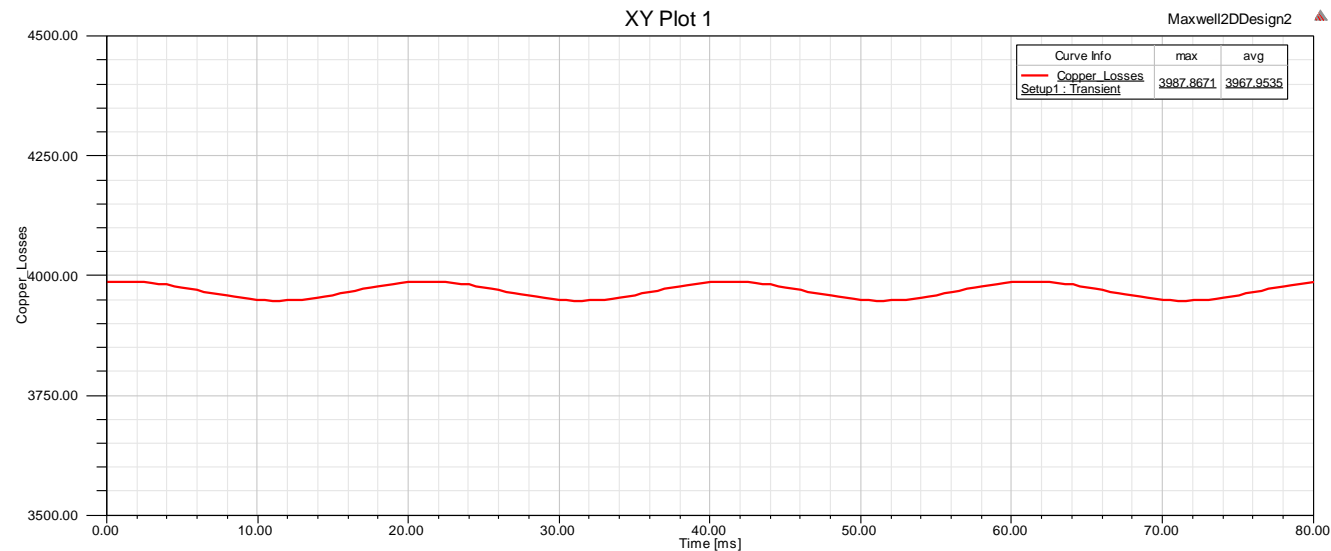

Fig. 7: The copper losses amount.

Investigation of the saturation gives designers an awareness of their design accuracy, so that if the flux density be higher than specified limit, it indicates that the calculated dimensions are less than what they should be. This comes into account as a defect in the design process. In Fig. 8 and Fig. 9, the amount of the flux density in the stator yoke and teeth are shown respectively.

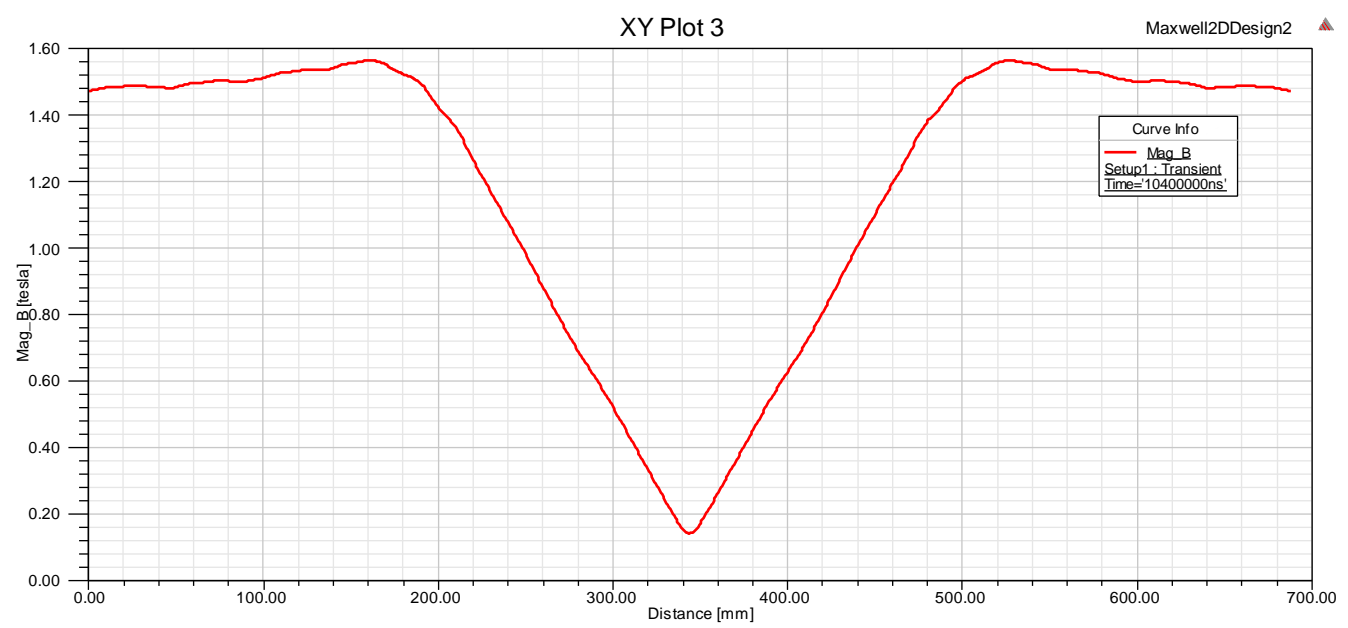

Fig. 8: The flux density changes in the stator yoke.

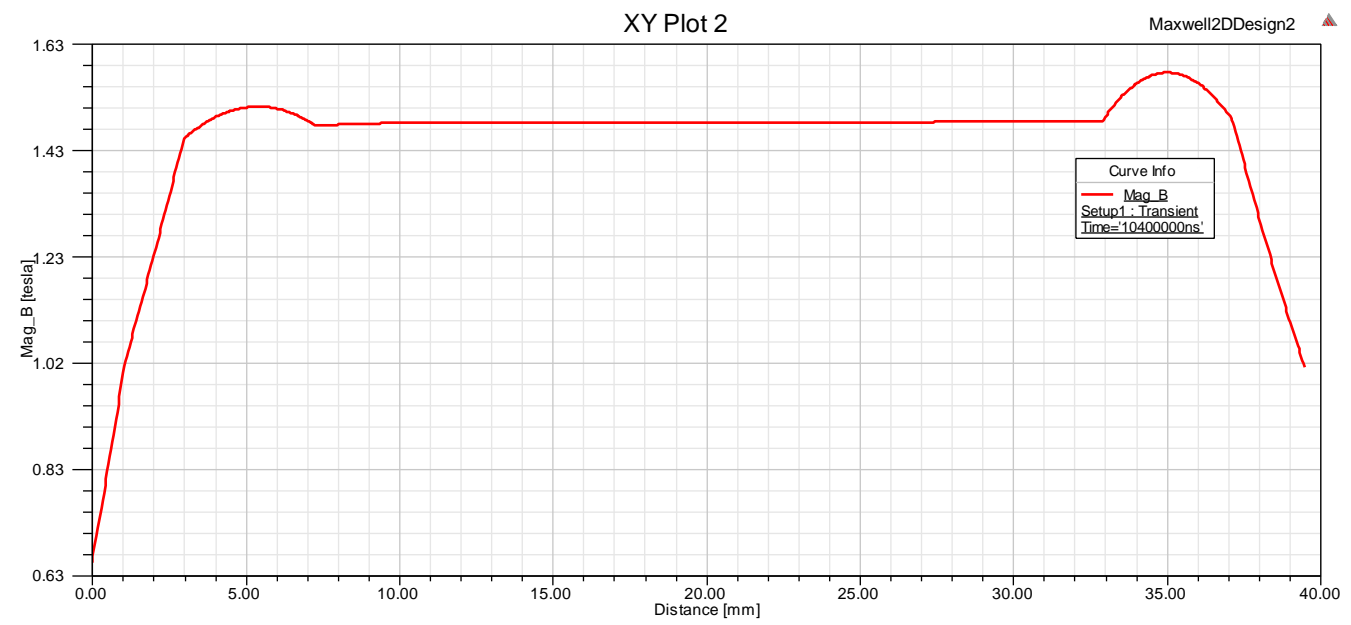

Fig. 9: The flux density changes in the tooth. 
According to Fig. 8 and Fig. 9, it can be found that the saturation does not occur in the whole stator. It should be noted that in Fig. 8, the maximum amount of the flux density is larger than the considered saturation density but is not significant and is acceptable in the design field. Also, to illustrate a better view of the saturation issue, a magnetic flux density throughout the motor is shown in Fig. 10. This figure confirms the validity of what was said about Fig. 8 and Fig. 9. Table 6 represents a comparison between the optimization results and the simulation results in this paper.

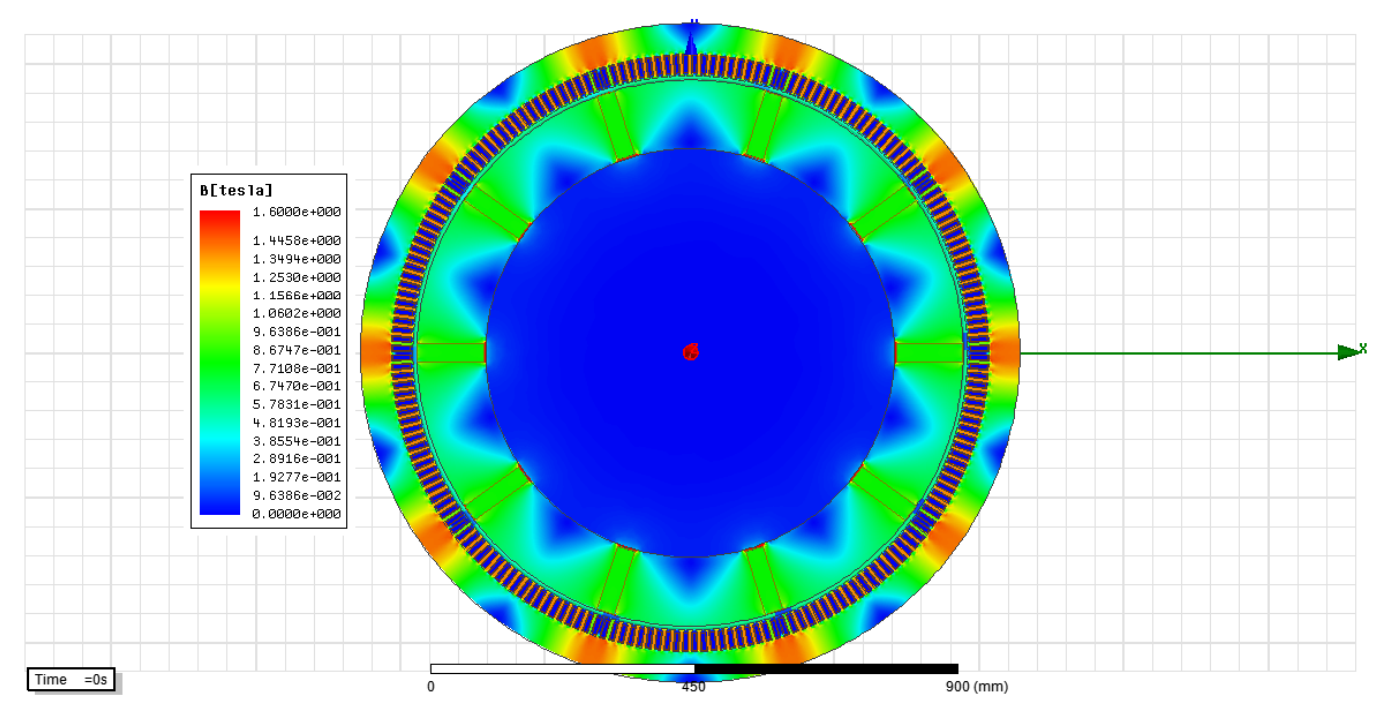

Fig. 10: Flux density distribution

Table 6: Comparison of results

\begin{tabular}{cccc}
\hline Parameters & FEA & Optimization & $\begin{array}{c}\text { Error } \\
(\boldsymbol{\%})\end{array}$ \\
\hline Rated Torque $(\mathbf{N m})$ & 15591.2 & 16200 & 3.9 \\
Copper Losses $(\mathbf{W})$ & 3968.6 & 4123.3 & 3.9 \\
Air Gap Flux Density $(\mathbf{T})$ & $\sim 0.59$ & 0.5851 & 0.83 \\
$\boldsymbol{E}_{\boldsymbol{f}} / \boldsymbol{V}_{\text {in }}$ & 0.77 & 0.81 & 5.19 \\
Current Density $\left(\mathbf{A} / \mathbf{m m}^{\mathbf{2}}\right)$ & 3.01 & 3 & 0.033 \\
\hline
\end{tabular}

\section{CONCLUSION}

In this paper, the optimum design procedure of a five-phase spoke type permanent magnet synchronous motor is presented. Then the optimization is performed by an ant colony optimization (ACO) algorithm with the aim of maximizing torque at the lowest volume to use as ship propulsion. Finally, the finite element simulation is used for validating the results of the optimization. Based on the results, the low percentage of errors show the validity and accuracy of the proposed design method.

\section{REFERENCES}

[1] Gieras JF. (2010) Permanent Magnet Motor Technology: Design and Applications. $3^{\text {rd }}$ ed. USA: CRC Press.

[2] Parsa L, Toliyat HA. (2005) Five-phase permanent-magnet motor drives. IEEE Transactions on Industry Applications, 41(1):30-37. 
[3] Sadeghi S, Parsa L. (2011) Multiobjective design optimization of five-phase Halbach array permanent-magnet machine. IEEE Transactions on Magnetics, 47(6):1658-1666.

[4] Parsa L, Goodarzi A, Toliyat HA. (2005) Five-Phase Interior Permanent Magnet Motor for Hybrid Electric Vehicle Application. IEEE Vehicle Power and Propulsion Conference, 631637.

[5] Parasiliti F, Villani M, Lucidi S, Rinaldi F. (2012) Finite-element-based multiobjective design optimization procedure of interior permanent magnet synchronous motors for wide constant-power region operation. IEEE Transactions on Industrial Electronics, 59(6):25032514.

[6] Tsampouris E, Kakosimos P, Kladas A. (2013) Coupled computation of electric motor design and control parameters based on ant colonies speed trajectory optimization. IEEE Transactions on Magnetics, 49(5):2177-2180.

[7] Zhang P, Ionel DM, Demerdash NAO. (2013) Morphing parametric modeling and design optimization of spoke and v-type permanent magnet machines by combined design of experiments and differential evolution algorithms. IEEE Energy Conversion Congress and Exposition, 5056-5063.

[8] Demir Y, Ocak O, Aydin M. (2013) Design Optimization and Manufacturing of A Spoke Type Interior Permanent Magnet Synchronous Motor for Low Voltage-High Current Servo Applications. IEEE International Electric Machines \& Drives Conference, 9-14.

[9] Mi CC. (2006) Analytical design of permanent-magnet traction-drive motors. IEEE Transactions on Magnetics, 42(7):1861-1866.

[10] Jannot X, Marchand C, Vannier JC, Gabsi M, Saint-Michel J, Sadarnac D. (2011) Multiphasic modeling of a high-speed interior permanent-magnet synchronous machine for a multiobjective optimal design. IEEE Transactions on Energy Conversion, 26(2):457-467.

[11] Gundugdu T, Komurgoz G. (2010) Design of permanent magnet machines with different rotor type. World Academy of Science, Engineering \& Technology, 4:468-473.

[12] Bianchi N, Bolognani S, Frare P. (2006) Design criteria for high-efficiency spm synchronous motors. IEEE Transactions on Energy Conversion, 21(2):396-404.

[13] Grauers A. (1996) Design of direct-driven permanent magnet generator for wind turbines. Chalmers University of technology. PhD thesis. Chalmers University of Technology, Göteborg, Sweden.

[14] Seong Taek L. (2009) Development and Analysis of Interior Permanent Magnet Synchronous Motor with Field Excitation Structure. PhD thesis. University of Tennessee, USA.

[15] Pyrhonen J, Jokinen T, Hrabovcov'a V. (2009) Design of rotating electrical machines. $1^{\text {st }}$ ed. Great Britain: CPI, 2009.

[16] Manninen A. (2012) Evaluation of the effects of design choices on surface mounted permanent magnet machines using an analytical dimensioning tool. MSc thesis. University School of Electrical Engineering, Aalto, Finland.

[17] Rodrigues Monteiro MS. (2012) Ant Colony Optimization Algorithms to solve Nonlinear Network Flow Problems. PhD thesis. University of Porto, Portugal, Faculty of Economics. 